\title{
"Feliz por morrer entre os índios e longe dos remédios humanos". Um estudo sobre as causas de mortes de jesuítas nas Cartas Ânuas da Provincia Jesuitica do Paraguai no século XVII.
}

"Happy to die amongst the Indians and away from human remedies". A study about the causae mortis of Jesuits in the Cartas Anuas of the Jesuitic Province of Paraguay in the $17^{\text {th }}$ century.

Eliane Cristina Deckmann Fleck ${ }^{*}$

Tarcila Nienow Stein ${ }^{* *}$

\section{Resumo}

Este artigo apresenta análise das Cartas Ânuas da Província Jesuítica do Paraguai do século XVII, em especial, dos necrológios, visando à identificação das causas mortis e das percepções sobre a morte e o morrer dos missionários da Companhia de Jesus. Os necrológios destacam os feitos mais relevantes - e edificantes - da trajetória dos jesuítas falecidos - do nascimento até a morte -, as dificuldades que enfrentaram em missão, os objetivos que não puderam ser alcançados e, principalmente, suas maiores provas de fé. Estas, invariavelmente, estão relacionadas à resignação diante da iminência da morte em decorrência de enfermidade ou martírio -, à maior ou menor resistência dos indígenas à conversão, às distâncias percorridas e às condições geo-climáticas das regiões em que atuavam como missionários. Além de trazer informações sobre como estes padres buscavam "la salud de las almas", enfrentando privações, ameaças constantes e obstáculos naturais para atender a grupos de indígenas, estes elogios fúnebres definem modelos de conduta virtuosa a serem observados, apontando para a função pedagógica e de consagração póstuma que eles desempenhavam para a Companhia de Jesus.

\section{Palavras Chave}

Província Jesuítica do Paraguai, Cartas Ânuas do século XVII, necrológios, causas de mortes

\footnotetext{
* É Pesquisadora do Conselho Nacional de Desenvolvimento Científico e Tecnológico (CNPq); Doutora em História pela PUCRS, de Porto Alegre, RS e Professora da Graduação e da Pós-Graduação em História da Universidade do Vale do Rio dos Sinos - UNISINOS, São Leopoldo.

** Graduada em História - UNISINOS. Atuou como Bolsista PROBIC-FAPERGS junto ao Projeto “Medicina e Missão" no período de 2011 a 2012.
} 


\begin{abstract}
This article presents an analysis of the Cartas Ânuas of the Jesuitic Province of Paraguay in the 17th century, especially those of necrologies, seeking to identify the causas mortis and the perceptions about death and the dying of the missionaries of the Company of Jesus. The necrologies highlight the most relevant - and edifying - deeds in the trajectory of the deceased Jesuits - from birth do death -, the hardships they faced in their mission, the goals that couldn't be reached and, primarily, their biggest proofs of faith. These are, invariably, related to the resignation facing imminent death whether due to disease or martyrdom -, to the greater or lesser resistance of the indigenes to conversion, to the distances covered and to the geographic and climatic conditions of the regions in which they acted as missionaries. Other than gathering information about how these priests seeked "la salud de las almas", facing deprivations, constant threats and natural obstacles to attend indigenous groups, this funereal praise defines virtuous conduct models to be observed, pointing to the pedagogic and posthumous consagration functions they performed for the Company of Jesus.
\end{abstract}

\title{
Key Words
}

Jesuitic Province of Paraguay, Cartas Ânuas of the 17th century, necrologies, causae mortis

\section{Recibido: 20 de mayo de 2013}

Evaluado: 26 de junio de 2013 


\section{“Porque a escritura queda y dá siempre testimonio": missionários virtuosos a serviço da "maior Glória de Deus"}

Dentre os objetivos principais da escrita na Europa dos séculos XVI e XVII, estava o de "forjar memoria de las cosas, de las ideas y de las personas por medio de la transmisión del conocimiento de sus hechos, sentimientos y pasiones", mas de uma memória entendida como "algo más que mera mnemotecnia, más que un simple artifício para recordar, y que, por contra, se elevaba como un verdadero arte para conocer personalmente y hacer posible el conocimiento ajeno."

Para a Companhia de Jesus, ordem religiosa surgida no contexto da ContraReforma, a memória "se configurava como uma das exigências institucionais para a ‘ajuda das almas'”. As Constituições da Companhia, de 1556, ${ }^{2}$ previam que, "além das faculdades da inteligência e da vontade”, seus membros deveriam demonstrar “"a capacidade de aprender e fidelidade para reter o que se aprende'”. ${ }^{3}$ A esta exigência - e para garantir a unidade da Companhia - o fundador da ordem, o basco Inácio de Loyola, ${ }^{4}$ agregou a orientação de que seus membros deveriam relatar e compartilhar suas experiências missionárias, pois "lo que se escribe es aún mucho mas de mirar que lo que se habla; porque la escritura queda, y da siempre testimonio, y no se puede así bien soldar ni glosar tan facilmente como quando hablamos". ${ }^{5}$ A prática epistolar, em razão disso, além de minimizar os efeitos da dispersão dos missionários a serviço do apostolado nas terras de missão, ${ }^{6}$ constituiu-se em forma bastante eficiente de aplicação das capacidades de "reter o que se aprende" e também de recordar. ${ }^{7}$

\footnotetext{
${ }^{1}$ Bouza, 1999: 16.

2 “As Constituições foram redigidas por santo Inácio entre 1541 e 1556. [...] primeiro só e depois, com ajuda de seu secretário, o Padre Polanco, foi avançando via consultas a diversos rascunhos e versões em 1547, 1550, até chegar às dez partes de 1556” (Torres Londoño, 2002: 31).

3 Vilar, 2006: 176. Em relação à formação do jesuíta, vale lembrar que desde a sua fundação, a Companhia sempre valorizou os aspectos relacionados às Letras, o que compreendia escrever e ler em vernáculo e latim, além de ter conhecimentos de outras línguas. No texto das Constituições da Ordem, estão referidos os impedimentos de ingresso para aqueles que não possuíam familiaridade com a cultura escrita: "Falta de letras o aptitud de ingenio o memória para aprendellas o lengua para explicallas" (Torres Londoño, 2002: 31).

${ }^{4}$ A Bula Papal Regimini militantis Ecclesiae, que institucionalizará a Companhia de Jesus, foi assinada em 27 de setembro de 1540. (García Villoslada, 1954: 50). De acordo com Blumers (1992: 20), “al fallecer al Padre Ignacio (nombre adoptado en Roma), el 31.7.1556, formaban la Compañia de Jesús casi un millar de miembros, entre sacerdotes, hermanos coadjutores y escolares en formación, repartidos por un centenar de casas, y organizados en 12 provincias creadas según este orden cronológico: Portugal, 1546; Índia, 1549; Etruria o Italia e Sicília, 1551; Gallia o Francia, 1552; Brasil, 1552; Aragon, Castilha y provincia itinerante, Etiópia, iniciada en 1555”. Conforme O’Malley (1993: 3), “by 1565 they were active in many countries of Western Europe, but also in Brazil, India, Japan, and elsewhere. They preached, taught catechism, proposed new sacramental pratices, and sought to help orphans, prostitutes, and prisioners in jail”.

${ }^{5}$ José Eisenberg debruça-se sobre o sentido e a dinâmica da correspondência epistolar jesuítica como mecanismo de organização e controle interno das atividades da Companhia, em sua obra As missões jesuíticas e o pensamento político moderno: encontros culturais, aventuras teóricas. Segundo este autor, "nas práticas relatadas através das missivas”, os missionários demonstravam sua capacidade de conjugar o modus procedendi da Companhia de Jesus, "uma dialética entre obediência e prudência resultante dos elementos voluntarísticos da doutrina espiritual de Inácio de Loyola” (Eisenberg, 2000: 19).

${ }^{6}$ A oitava parte das Constituições da Companhia de Jesus, denominada Meios de unir com a Cabeça e entre si aqueles que estão dispersos, define que a correspondência epistolar se encarregaria de unir "súditos e Superiores, com intercâmbio freqüente de informações entre uns e outros, e o conhecimento das notícias”. Além das correspondências escritas entre o Geral, os Provinciais, os Superiores locais, os
} 
A Companhia não se limitou, contudo, à prática epistolar para o atendimento da orientação de "glosar y dar siempre testimonio", recorrendo a outras formas de escrita para a instituição de "suportes de recordação" ${ }^{\text {, }}$ tais como as crônicas, os memoriais, as biografias e as sínteses históricas elaboradas por historiadores oficiais. De acordo com Efraim Cardozo, "Desde la época temprana de su definitiva radicación en el Paraguay, la Compañía de Jesús se encargó de tener [una historia oficial de la Província Jesuítica del Paraguay]", atribuindo sua elaboração a "sujetos de su seno, calificados por sus luces y sus letras", 9 que tinham como principal objetivo "historiar los esfuerzos evangelizadores cumplidos por la Compañía." 10

Em todos estes gêneros narrativos, independentemente da sua função primordial ou destinação, constata-se o recurso à consagração póstuma, que consiste na destinação de um indivíduo de exemplar devotamento ao que poderíamos denominar de "templo da memória”. Ao destacar as virtudes do morto e silenciar sobre suas imperfeições recorrendo a um procedimento seletivo de "esquecimento" -, tanto as biografias, quanto os necrológios ${ }^{11}$ dos mais destacados jesuítas se caracterizam por exaltar a exemplaridade de suas condutas que deve ser recordada. ${ }^{12}$ Ao ser acionada por missionários e indígenas, esta memória parece não apenas evocar a busca pelo martírio - que muitos jesuítas procuraram alcançar nas terras de missão - e, consequentemente, o revigoramento do ideal apostólico da Companhia de Jesus -, mas, também, de um passado "que assim se torna mestre do futuro, [através das] sombras venerandas de alguns mortos que parecem surgir incessantemente do abismo das sepulturas para mostrar aos vivos a estrada do dever [...] e da honra."

Reitores e os enviados em missão, os casos de edificação deveriam ser divulgados a todos os membros da Ordem em cartas escritas - uma em latim e, a outra, em vernáculo - a cada quatro meses e endereçadas ao Provincial. O Provincial enviaria estas cartas duplicadas ao Geral, junto com uma carta sua que contasse “fatos importantes ou edificantes omitido nas primeiras”. Cópias dessas correspondências seriam utilizadas para propagar a edificação entre os outros membros da Ordem. (Loyola, 2004: 191-192)

${ }^{7}$ Torres Londoño, 2002: 13.

${ }^{8}$ Os necrológios estão entre os textos considerados de natureza hagiográfica que possuem como temática central a biografia e os feitos de um determinado indivíduo, com o objetivo de instruir e edificar os cristãos na fé, sendo, consequentemente, importantes veículos para a propagação de concepções teológicas, modelos de comportamento, padrões morais e valores.

${ }^{9}$ Nas Constituições, Inácio Loyola se deteve também na formação do jesuíta, pois acreditava que o conhecimento contribuiria para que os propósitos de ajuda ao próximo, do conhecimento do amor de Deus e a salvação da alma fossem alcançados. Seus membros deveriam se dedicar ao estudo da Teologia (Teologia Moral, Escrituras, Direito Canônico e Teologia Positiva) e da Filosofia (Escolástica). Além de conhecer profundamente Teologia, um jesuíta deveria também dominar áreas como Gramática, Retórica, Poesia e História, Lógica, Física, Metafísica, Matemáticas, Filosofia Natural, Filosofia Moral e línguas antigas e modernas. Para desenvolver a caridade, a oração, a fé, o amor e a obediência - sem as quais o engenho, a imaginação e a razão não poderiam dar frutos - as Constituições previam exercícios espirituais e peregrinações.

${ }^{10}$ Cardozo, 1959: 270.

${ }^{11}$ Os necrológios se constituem de elogios fúnebres que integravam o texto das Cartas Ânuas. Além da função de informar ao padre geral da Companhia sobre os óbitos ocorridos durante determinado período, apresentavam um relato da trajetória do jesuíta que faleceu, enaltecendo suas virtudes e desprendimento, já que "La vida de un jesuita "virtuoso", una vez desaparecido, se convertia en atractiva para su imitacion” (Burrieza Sánchez, 2009: 523).

12 Segundo Maurice Halbwachs (1990: 81), a memória retém do passado apenas o que “é capaz de viver na consciência do grupo que a mantém”.

${ }^{13}$ Leonzo, 1983: 86-84.

26 Eliane Cristina Deckmann Fleck y Tarcila Nienow Stein. "Feliz por morrer...” 24-43. 
Nesse sentido, pode-se afirmar que a construção de uma memória sobre a atuação da Companhia de Jesus no Novo Mundo, a partir da valorização das atuações de determinados indivíduos, se propõe, de fato, a garantir uma visão positiva do trabalho realizado pela Ordem por cerca de 160 anos. ${ }^{14}$ Nas Cartas Ânuas ${ }^{15}$ escritas pelos missionários enviados para as longínquas terras de missão, as dificuldades e os desafios próprios do apostolado são constantemente mencionados, ${ }^{16}$ com destaque para as privações e os perigos que enfrentavam ao longo dos caminhos que percorriam dentro e, às vezes, fora dos limites da Província Jesuítica do Paraguai. ${ }^{17}$

Na segunda metade do século XVII, os jesuítas se dedicaram às missões para “cosecha de almas”, que partiam dos colégios em direção às regiões e às populações indígenas que a Companhia havia definido como novos alvos de sua atuação. ${ }^{18}$ Dentre as missões que são constantemente mencionadas, estão as promovidas pelo Colégio de Salta em direção ao Vale del Calchaquí, e que visavam converter aos índios calchaquís, os pullares, os humacas e outros. ${ }^{19}$ Na Carta de 1650-52, o vale habitado por estes grupos indígenas é descrito como "bastante angosto, entra por allí por varios días de camino, y sus habitantes viven en las pendientes casi inaccesibles de las montañas, parte en cavernas, parte en toldos y ranchos" ${ }^{20}$. Segundo o redator da Ânua, dada a condição do relevo, em especial, os "Yacobileos [...] dejan morir de hambre a sus sacerdotes, no trayéndoles ni agua del río."21

Se as populações indígenas contatadas são descritas como não hospitaleiras, a região norte da Província Jesuítica do Paraguai não recebeu melhor avaliação, como se constata na informação dada pelo padre De La Mota, de que "me ví muchas veces

\footnotetext{
${ }^{14}$ A Companhia de Jesus instalou sua primeira missão na Província do Paraguai em 1607, sendo expulsa dos domínios coloniais americanos da Coroa espanhola em 1767 (Barnadas, 2008).

${ }^{15}$ Vale lembrar que as cartas jesuíticas fornecem valiosas informações também sobre as práticas culturais indígenas, devido às orientações que guiavam a sua produção e circulação: a sistematização e a socialização do conhecimento adquirido pelos padres, tendo em vista o aprimoramento da experiência missionária. Cabia a esta correspondência unir, por meio da escrita, os diversos e esparsos membros da Companhia de Jesus, mantendo a hierarquia da Ordem; promover uma propaganda edificante que inspirasse novas adesões e dividir as experiências alcançadas de maneira a tornar as missões mais frutíferas pela troca de informações.

${ }^{16}$ Em relação às Cartas Ânuas, deve-se observar que têm sua base nos relatórios anuais que o Provincial recebia dos superiores das residências, colégios, universidades e missões junto aos índios. Continham uma detalhada informação sobre as casa, suas obras, pessoas e atividades, sendo redigidas pelos secretários ou por pessoas com capacidade para escrevê-las, designadas pelo Provincial. As Ânuas relativas à Província Jesuítica do Paraguai cobrem o período que vai de 1609 a 1675 e, após um intervalo de cerca de quarenta anos, o período de 1714 a 1762. Obedeceram a uma periodicidade anual até 1617, quando passaram a ser bienais e, posteriormente, trienais.

17 De acordo com Ivone Del Valle, a escrita e a conseqüente troca de informações, através de cartas ou informes, "era parte importante del ejercício de recrear su universo original: práctica de conjuo que negaba la disparidad entre el lugar de enunciación físico (las fronteras, las márgenes del mundo ‘civilizado') y el mental." (Del Valle, 2009: 70). Diante das dificuldades, da solidão (do desgaste físico e psicológico) e do distanciamento das referências de civilização e da própria Companhia de Jesus, a escrita e a leitura eram o recurso, que perpassado pela imaginação, empregado para garantir a sanidade mental e, especialmente, para a renovação da fé e do ânimo para o atendimento dos objetivos traçados.

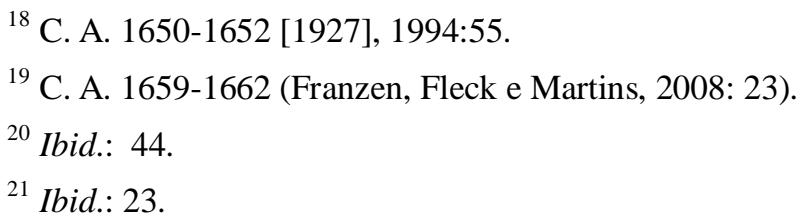


forçado a apearme, para no caer abajo juntamente con la mula.”22 O jesuíta estava, na verdade, se referindo às montanhas que compõem a Cordilheira dos Andes, e que, com certeza, impõem - até os dias atuais - dificuldades tanto de acesso, quanto de locomoção aos viajantes. Ao descrever o caminho percorrido pelo Vale del Calchaquí, o padre De La Mota informa que "por las pedregosas pendientes de la mantaña, al borde de los precipícios" somente consegue resistir "sacudidos por los vientos frios", inspirado por "Dios en bien de la eterna salvación de estos bárbaros." ${ }^{23}$ Cabe ressaltar que estas missões "para las vastas regiones de los calchaquíes" foram interrompidas, devido às sublevações desses indígenas, que não aceitaram a dominação espanhola e a pregação dos missionários. Neste caso, "el gobernador de la província mobilizo um ejercito y emprendió una expedición militar para castigar a los rebeldes." 24

Além das missões que partiam em direção ao Vale del Calchaquí, outras se dirigiam ao Chaco, saindo de Jujuy, também instalada numa região montanhosa e com vales muito profundos, o que dificultava, sobremaneira, as expedições de missionários. Segundo Lorenzo Sobriño, aquelas que partiam de Jujuy em direção ao norte, passavam por "una cadena de montañas escarpadas tras de la otra, conduciendo el sendero al borde de terribles precipicios", o que tornava "el camino tan horrible, que no podría pasar por allí un reptil, y apenas un pájaro.” ${ }^{25}$ Apesar destas condições desfavoráveis, um dos missionários - o septuagenário padre Juan Pastor -, teria suportado "frio, nevazones y temporales no sólo con paciencia, sino con buen humor.”26

O relato de Sobriño prossegue, informando que "helábalos la lluvia fria, y abligábalos el aspero camino a andar a pie, a trepar por las empinadas cumbres", e que, diante disto, parar de andar era uma tarefa difícil, pois o vento era "tan huracanado que soplaba allí" que se "alborotaban las mulas." 27 Em relação à região dos vales, a Carta nos revela que "nada tenían de atractivo, tan desiertas y pantanosas que eran, y tan oscuras y sombrías por impedir la altura de los montes la luz del sol." ${ }^{28}$ Todas estas dificuldades, no entanto, teriam sido vencidas pelos missionários "por el celo por la gloria de Dios, y la salvación de las almas" e, assim, "quedaron atrás los montes, ríos, selvas, pantanos, y entraron en la región del Chaco" "29. Passados alguns anos, na Carta de 1672-1675 encontramos outra descrição sobre a região do Chaco, na qual o padre Cristóbal Gómez destaca que "La parte meridional [del gran Chaco] está rodeada por las provincias u diócesis de Chuquizaca, de Santa Cruz de la Sierra, del Tucumán, del Paraguay y del Rio de la Plata; mientras su parte setentrional se confunde con los domicilios de los indios del Brasil y del rio Marañón, hacia las regiones de Nueva Granada. $^{30}$

\footnotetext{
${ }^{22}$ C. A. 1652 [1927], 1994: 46.

${ }^{23}$ Ibid.: 46.

${ }^{24}$ C. A. 1659-1662 (Franzen, Fleck e Martins, 2008: 49).

${ }^{25}$ C. A. 1652 - 1654 [1927], 1994: 4.

${ }^{26}$ Ibid.: 4.

${ }^{27}$ Ibid.: 4.

${ }^{28}$ Ibid.: 4.

${ }^{29}$ Ibid.: 4.

${ }^{30}$ Ibid.: 31.
} 
Já o Itatim, localizado na planície central do continente, estava sob a responsabilidade do Colégio de Assunção. Com altitudes variando entre 80 e 150 metros e entrecortada pelo rio Paraguai, a região que conhecemos atualmente com a denominação de Pantanal, era muito propensa a inundações. Com o objetivo de evangelizar os índios desta região - "un innumerable gentio salvaje.”31 -, muitas missões volantes foram realizadas, sendo, posteriormente, estabelecidas reduções junto a estas populações nativas, como se pode depreender da informação que consta na Carta de 1650-1652, de que existiam "dos pueblos, el de San Ignacio, y el de la Nuestra Señora de la $\mathrm{Fe}^{\text {"32. }}$. Nesta mesma Carta, De La Mota reclama da retirada forçada dos missionários jesuítas da região, solicitada pelo Bispo Cárdenas devido ao conflito com a Companhia de Jesus.

Resolvida a situação, nos inícios da década de 1650, a assistência aos povoados do local veio a ser retomada - com muito trabalho - pelos missionários, já que, de acordo com De La Mota, "los pobles indios así maltratados tuvieron que huir a sus antiguos montes, hallándose más seguros entre los tigres que entre esta clase de párocos."33 A fim de cumprir as visitas periódicas, o jesuíta relata que havia sido aconselhado a não se dirigir à região sem escolta militar, por causa das "dificuldades de los viajes fluviales. "34 e dos ataques dos Payaguás, índios canoeiros que dominavam o rio Paraguai, ao norte de Assunção. De acordo com o registro feito na Ânua, De La Mota conseguiu chegar "solo armado con la cruz" 35 , tendo encontrado o padre Justo Mancilla, "guapo como ántes, caminando por las tupidas selvas y montes, para recoger a los escondidos, hallando buen número de estos infelices, y llevándolos al pueblo" 36 . Não deixou, no entanto, de registrar que Mancilla e outros missionários se encontravam nas condições mais miseráveis possíveis, com suas sotainas quase totalmente destruídas e "medio muertos de hambre." 37

O que se constata como um padrão narrativo nestes relatos sobre as missões campestres é que, em nenhum momento, os missionários envolvidos se mostram abalados em sua fé diante das dificuldades impostas pela geografia, quer estejam eles atuando no alto das montanhas andinas ou nos pântanos próximos de Assunção. Pelo contrário, estas experiências, socializadas através da intensa correspondência mantida entre os membros da Companhia de Jesus, se constituem em fator de enaltecimento do trabalho missionário e de justificativa para a continuidade do apostolado, reforçando a identidade do grupo e atendendo a uma das orientações de Santo Inácio, que era a de "glosar y dar siempre testimonio".

\footnotetext{
${ }^{31}$ C. A. 1650 - 1652 [1927], 1994: 42. Nesta referência à selvageria dos indígenas do Itatim, constata-se aquilo que Hansen denomina de "gênero oratório demonstrativo", que por desqualificar o "Outro", acaba por justificar a necessidade de civilização e de assistência espiritual e, consequentemente, por legitimar todo o investimento dos missionários e, sobretudo, por exaltar os perigos e dificuldades a ele associados. (Ver mais em Hansen, 2000).

${ }^{32}$ C. A. 1650 - 1652 [1927],1994: 42.

${ }^{33}$ Ibid.: 42.

${ }^{34}$ Ibid.: 42.

${ }^{35}$ Ibid.: 43.

${ }^{36}$ Ibid.: 43.

${ }^{37}$ Ibid.: 43.
}

29 Eliane Cristina Deckmann Fleck y Tarcila Nienow Stein. "Feliz por morrer...” 24-43. 


\section{Nos necrológios, a consagração póstuma a serviço da Companhia de Jesus}

O enaltecimento do trabalho missionário fica bem evidenciado nos necrológios ou obituários -, inseridos nas Ânuas que consultamos, e que nos oferecem ricas informações sobre a trajetória de alguns missionários jesuítas e as representações de que seus "incansables trabajos" foram alvo. ${ }^{38}$ Em cada uma dessas necrologias há uma pequena biografia do padre ou do irmão que faleceu durante o período abrangido pela carta e, nelas, aparecem algumas das viagens que realizou durante sua vida. Deve-se esclarecer que alguns necrológios são muito breves, enquanto outros, como o do padre Pedro de Mola, que encontramos na Carta de 1659-1662, oferecem uma maior riqueza de detalhes sobre a trajetória do missionário.

Segundo sua necrologia, o padre Pedro de Mola nasceu em Aragón, na Espanha, a 17 de janeiro de 1602, tendo fugido muito jovem de casa, devido aos maus tratos aplicados por sua madrasta. Acolhido pela Companhia, aos 19 anos de idade, em 31 de agosto de $1619^{39}$, foi admitido como noviço. Como nos conta Andrés de Rada, ainda durante seu noviciado, Mola solicitava constantemente aos seus superiores para ser enviado às "misiones de indios (...) en aquellas dilatadas regiones" ${ }^{40}$. Após obter a permissão e chegar a Buenos Aires, concluiu seus estudos e foi autorizado a ir "a las tan ansiadas misiones" ${ }^{41}$. À época da obtenção da autorização por Mola estava sendo implantada - pelo padre Antonio Ruiz de Montoya - a frente missionária do Guairá, este o incumbiu de "fundar el pueblo de San Miguel." "42 No entanto, ao chegar ao local, pôde constatar que já estava "bastante adelantado", ${ }^{43}$ não havendo a necessidade de sua permanência. Desse modo, partiu para San Antonio, que ficava próximo dali.

Em pouco tempo, os bandeirantes paulistas invadiram e destruíram todos esses povoados jesuítico-guaranis. Não por acaso, San Antonio e San Miguel foram os primeiros a ser atacados, devido a sua proximidade de São Paulo, que concentrava mamelucos profissionais no apresamento de índios, preferencialmente daqueles que possuíssem algum conhecimento agrícola, como os guaranis reduzidos. O padre Mola presenciou as atrocidades e a destruição promovidas pelos paulistas ${ }^{44}$. Sem armas para defender o povoado pelo qual era responsável - e sem qualquer alternativa - fugiu e perdeu-se, tendo sido encontrado "ronco de hambre y sed" 45 , "en unos montes que sólo son la morada de fieras" 46 pelo padre Silvério Pastor.

Após estes acontecimentos foi enviado à região do Tape, juntamente com o irmão Antonio Bernal, tendo lhes sido designado o povoado de Jesus Maria, local mais avançado dos domínios espanhóis no território do atual Rio Grande do Sul, que se

\footnotetext{
${ }^{38}$ C. A. 1659-1662 (Franzen, Fleck e Martins, 2008: 34).

39 Storni, 1980: 184.

${ }^{40}$ C. A. 1659-1662 (Franzen, Fleck e Martins, 2008: 72).

${ }^{41}$ Ibid.: 73.

${ }^{42}$ Ibid.: 73 .

${ }^{43}$ Ibid.: 73.

44 Especificamente a invasão assistida pelo jesuíta foi ordenada por Raposo Tavares e comandada por Simão Álvares, em 30 de janeiro de 1629 (Aguilar, 2002: 264).

${ }^{45}$ C. A. 1659-1662 (Franzen, Fleck e Martins, 2008: 74).

${ }^{46}$ Ibid.:73.
}

30 Eliane Cristina Deckmann Fleck y Tarcila Nienow Stein. “Feliz por morrer...” 24-43. 
localizava na margem direita do Rio Pardo, próximo da foz do Rio Pardinho ${ }^{47}$. Não há informação sobre atuações do padre Pedro de Mola em outras reduções após esta data, havendo apenas menção a sua morte, sem especificação do local em que ocorreu. Deduz-se que tenha ocorrido na redução de San José, pois além de nela ter prestado alguns serviços ${ }^{48}$, seu necrológio, que integra a Carta de 1659-1662, localiza-se logo após os relatos feitos sobre esta redução, e antecedendo as informações sobre o ocorrido neste mesmo período na redução de Mártires del Japón. No entanto, segundo Storni ${ }^{49}$, sua morte teria ocorrido em Santos Apóstoles, redução localizada próximo da de San José.

Os necrológios como já referido, destacam os feitos mais relevantes - e edificantes - dos missionários jesuítas, desde o seu nascimento até sua morte. Nelas, são destacadas as dificuldades que estes padres enfrentaram, seus maiores sucessos e, principalmente, suas maiores provas de fé. Invariavelmente, essas mostras de fé estão relacionadas às distâncias percorridas, às adversidades climáticas e às condições sobretudo, as de relevo e de vegetação - das regiões que percorreram atuando como missionários. Nestes obituários podem ser encontradas várias referências a distâncias, a condições de terreno e, por vezes, algumas relacionadas a ambos os temas. São ressaltadas, em especial, as longas distâncias percorridas e as viagens intermináveis, enfatizadas com o objetivo de atestar o empenho constante e a fé demonstrada pelo missionário diante das dificuldades.

De acordo com o padre relator, somente o ardor missionário e a fé poderiam justificar a resignação com que estes jesuítas percorriam lugares inóspitos, atravessavam rios e pântanos, passavam fome e se defrontavam com populações indígenas hostis. Assim, as inúmeras demonstrações de fé, virtude e dedicação do missionário falecido são enaltecidas pelo narrador, com a intenção de servir de inspiração aos jovens missionários, o que fica evidenciado na afirmação feita por Andrés de Rada de que "tuviera yo que alargar demasiado esta narración al enumerar los actos de heroica virtud, que ejercía con su constancia en el camino una vez emprendido."50

Apesar de terem sido redigidos por diferentes padres e em períodos distintos, constata-se neles a presença do mesmo padrão de exaltação dos feitos dos jesuítas falecidos evidenciados nos dois necrológios que analisamos anteriormente: os missionários jesuítas - movidos e fortalecidos pela fé - não temeram as distâncias, as selvas, o frio, o calor, os rios caudalosos, a altitude das montanhas ou qualquer outra dificuldade que se lhes apresentou. Dentre as inúmeras demonstrações irrefutáveis de fé, destacamos aquela que refere que o irmão Antonio Bernal ${ }^{51}$ não se incomodava em fazer a pé um trajeto de 100 léguas, que o padre Juan de Humanes não se importava em atender a qualquer hora e sob qualquer condição climática e, ainda, que o padre Diego de Salazar aceitou, resignadamente, permanecer isolado de qualquer contato por 42 anos, dedicando-se, integralmente, ao trabalho missionário junto aos indígenas.

\footnotetext{
${ }^{47}$ Becker, 1992: 177.

${ }^{48}$ Em Carta de 1628, dirigida pelo Antonio Ruiz de Montoya ao Padre Provincial, encontra-se a seguinte informação: "na redução de San José encontrava-se o padre Pedro Mola sendo amado afetuosamente pelos índios”. (Aguilar, 2002: 246)

49 Storni, 1980: 187.

${ }^{50}$ C. A. 1668 [1927],1994: 11.

51 O irmão Antonio Bernal nasceu em Portugal em 1582, ingressou na Companhia em 20/08/1615, e morreu em Córdoba, em 13/04/1661 (Storni, 1980: 37).
} 
A enfática reafirmação da inabalável fé dos jesuítas no cumprimento de sua missão é padrão narrativo recorrente nas Cartas Ânuas, cujos relatos tinham, dentre os seus objetivos, o enaltecimento da própria Companhia e de sua obra. Em se tratando das necrologias, constata-se que a vida de cada missionário deveria ser resumida em poucas palavras, com destaque para os seus maiores feitos. Desse modo, as dificuldades geográficas apareciam com a mesma recorrência que as questões relacionadas ao trato com as populações indígenas, por exemplo, ou com as dificuldades com as autoridades locais, ou mesmo, a difícil relação da Companhia com o clero secular. As necrologias, portanto, trazem em maior número - e com maior força narrativa - as representações de uma geografia indomável e inóspita e da desgastante tarefa de transpô-la.

Assim, os rios, vales, campos, florestas, montanhas e tudo o mais que caracterizasse o caminho percorrido pelo missionário, serviam como prova de fé, não restando outra alternativa a não ser enfrentar e superar tal dificuldade. Neste tipo de relato, as dificuldades são sempre vencidas; a geografia, embora muito difícil de ser enfrentada, é sempre apenas um obstáculo, que, no entanto, não significa impedimento, mas, sim, uma forma de testar a fé e ressaltar as qualidades do missionário.

O emprego de expressões como a de que o missionário "volvia a pie»52 ou que ia "para explorar aquellas selvas (...) en cima de las montañas, a través de ríos (...) [e] intransitables caminos" 53 contribuem para ressaltar os grandes esforços empreendidos pelos missionários em face da geografia da região que percorriam. Assim, o relevo, a vegetação e o clima aparecem como pano de fundo essencial para os relatos edificantes: os rios são 'dilatados' em sua extensão ou profundidade; o clima é descrito como de 'grandes calores'; a selva na qual adentravam 'escondia os bárbaros' e as montanhas ou montes são 'empinados’ e difíceis de vencer. Os péssimos caminhos percorridos 'custavam vidas' e as distâncias eram tão grandes que implicavam décadas de isolamento. É neste cenário que se desenrolaram as histórias de vida dos missionários a que temos acesso nos necrológios dessas Cartas. As descrições do relevo, do clima e da vegetação que encontramos nas Ânuas não destoam do real encontrado ou vivido pelos missionários. Suas representações, no entanto, são superdimensionadas e usadas magistralmente como recursos discursivos para a comprovação e a valorização dos trabalhos desenvolvidos pelos padres da Companhia de Jesus. As grandes viagens e as grandes distâncias são, de fato, argumentos irrefutáveis de que os trabalhos se realizavam em condições-limite e que exigiam grandes esforços.

As dificuldades encontradas são, a certa altura, comparadas aos Doze Trabalhos de Hércules, como nesta passagem que destaca que o padre Juan Contreras "hubiérase hasta un Hércules (...) en especial, cuando tuvo que registrar los montes, para buscar os fugitivos" ${ }^{\text {54 }}$. Vale lembrar que os Trabalhos de Hércules estão relacionados a grandes desafios, tais como o de matar leões invencíveis e dragões de cem cabeças; limpar, em apenas um dia, currais que comportavam três mil bois, ou então, perseguir animais incansáveis que, somente com a obstinação de um herói mitológico poderiam vir a ser executados. Ao estabelecer esta comparação - entre o missionário e o herói mítico -, o redator da Ânua enaltece as dificuldades encontradas por todos os missionários que atuavam na Província Jesuítica do Paraguai, vinculando-as às criaturas mitológicas e aos desafios que apenas um herói conseguiu vencer.

\footnotetext{
${ }^{52}$ C. A. 1659-1662 (Franzen, Fleck e Martins, 2008: 37).

${ }^{53}$ Ibid.: 78.

${ }^{54}$ C. A. 1668 [1927], 1994: 18.
} 
O certo é que este tipo de "elogio fúnebre” se aproxima bastante das histórias de vida dos santos, nas quais o martírio e a virtude cristã são exaltados, a exemplo de algumas condutas de jesuítas descritas nas necrologias. Esta pretensa "invencibilidade" do missionário jesuíta, segundo Berto ${ }^{55}$, pode ser observada na atitude "dos religiosos frente aos 'obstáculos' naturais [pois] não sofrem ferimentos ao cair da montaria (...) estão imunes aos perigos de ventanias e tormentas”. Se algum desses missionários não consegue vencer tais obstáculos, a justificativa é a de que "fatalmente acontecem devido à conduta mártir, para a qual estavam destinados”. Portanto, a lógica da narrativa gira em torno da construção de um discurso edificante, em que as dificuldades encontradas, tanto aquelas decorrentes dos deslocamentos, quanto aquelas resultantes de eventos climáticos são, invariavelmente, resolvidas com demonstrações de fé dos próprios religiosos ou da população por eles atendida.

As Cartas Ânuas da segunda metade do século XVII e, em especial, os necrológios, permitem a reconstituição dos cenários de atuação da Companhia de Jesus na vasta área que constituía a Província Jesuítica do Paraguai. Estes cenários, no entanto, devem ter suas descrições textuais condicionadas à intenção dos relatos e inseridas em seu contexto de produção. Assim, as descrições dos perigos e desafios enfrentados que os missionários enfrentaram ao se deslocarem pelo território da Província Jesuítica do Paraguai não deixaram de assumir uma função edificante, legitimando o apostolado jesuítico e servindo de exemplo aos missionários enviados para as diferentes regiões em que a Companhia de Jesus atuava. ${ }^{56}$ Muitas das descrições sobre o clima, relevo, hidrografia e vegetação que encontramos nas Ânuas, no entanto, acabariam se tornando também referência para o conhecimento da geografia americana ao longo do século XVII e, especialmente, no séculos seguinte.

\section{Nas Ânuas, os indícios sobre as causas mortis e sobre as atitudes diante da iminência da morte}

Segundo as orientações do fundador da Companhia de Jesus, os missionários deveriam pautar sua vida pela virtude, encarando as privações e os desafios com destemor e de forma resignada, o que pode ser observado de forma exemplar nos necrológios. Neste tópico, nos detemos na identificação das causas mortis e na análise das atitudes tanto de padres enfermos na iminência da morte, quanto de padres que se viram diante do martírio referidas nestes obituários.

Dentre as causas mortis de missionários que os necrológios referem (vide Figura 1), encontramos a idade avançada e aquelas associadas às condições adversas, sobretudo, as climáticas, que eram experimentadas tanto pelos padres que viviam nos colégios, quanto por aqueles que atuavam nas reduções. Em relação às reduções, é preciso considerar que algumas delas contavam com instalações precárias, desprovidas de hospital ou botica, dificultando a assistência aos padres e indígenas e implicando no agravamento das condições dos doentes ou na morte. Em alguns dos casos que

\footnotetext{
55 Berto, 2005: 75.

56 “A história deve respeitar as exigências da memória, necessárias para curar as infinitas feridas, mas, ao mesmo tempo, ela deve reafirmar a especificidade do regime de conhecimento que lhe é próprio, o qual supõe o exercício da crítica, a confrontação entre as razões dos atores e as circunstâncias constrangedoras que eles ignoram, assim como a produção de um saber possibilitada por operações controladas por uma comunidade científica.” (Chartier, 2010: 12).
} 
analisamos, se constata o desejo expresso de morrer pelo padre adoentado, que recusa qualquer remédio ou atendimento, como se pode perceber no trecho abaixo:

Otra vez fue sacado medio muerto de un río muy crecido, al cual quería pasar en una miserable canoa de corteza, para acudir a un enfermo. Tuvo que confesar repetidas veces a un hombre enfermo que exhalaba olor pestilencial, tanto que nadie se atrevía a acercársele (...) El mismo Padre se enfermó a consecuencia de aspirar tal olor, y tuvo que sufrir bastante tiempo. Pues se le ulceró la garganta y, tuvo que operarse la campanilla, así que casi perdió la voz. Pero por estos inconvenientes no se detuvo de sus actos caritativos de asistir a los moribundos (...) Hasta siguió, aunque con trabajo, catequizando y predicando a la gente ruda y española, siendo también muy concurrido su confesionario. Siguió hasta su avanzada edad con sus austeridades, disciplinándose en la iglesia muy entrada la noche, tanto que la gente de afuera que lo oía se espantaba. Al fin, después de una larga enfermedad, murió este santo varón. ${ }^{57}$

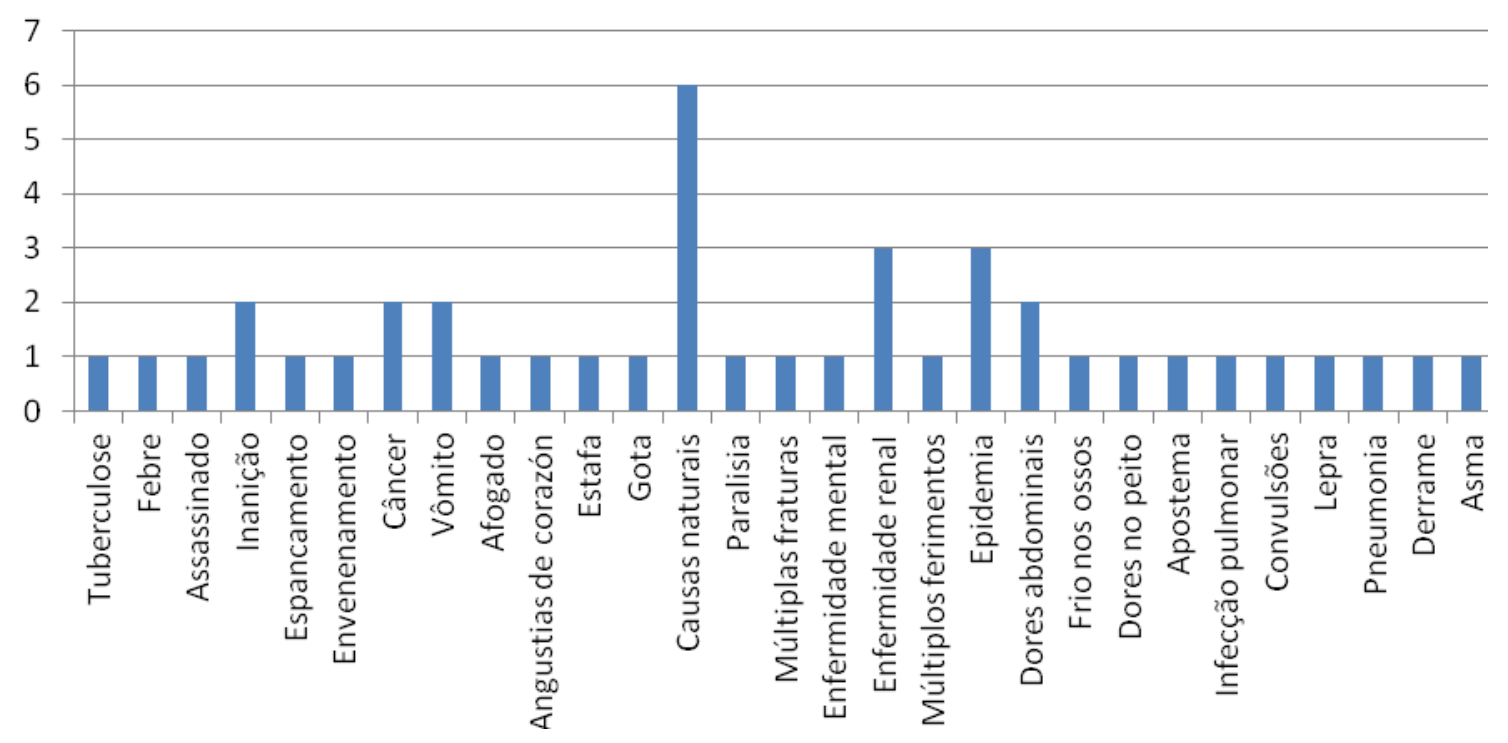

Figura 1: Causas das mortes de missionários

Foi possível constatar que as doenças que causavam a morte de padres que se encontravam nos colégios são diferentes daquelas que causaram a morte dos que viviam junto aos indígenas nas reduções. Vale lembrar que alguns colégios, tal como o de Córdoba, estavam equipados com boticas, contavam com enfermeiros, boticários e médicos, o que implicava, na maioria das vezes, na adoção de medidas profiláticas, de isolamento dos doentes e na administração de medicamentos previamente testados. Já os padres que atuavam junto às reduções, estavam mais propensos ao contágio em situações de epidemia, pois, pela própria natureza do seu trabalho apostólico, entravam necessariamente em contato com os indígenas enfermos, como nos mostra a citação abaixo:

(...) recorriam as casas dos enfermos, tanto para levar os consolos espirituais, como para ver se estavam bem assistidos, procurando que não lhes faltasse o alimento conveniente ao seu estado e para administrar as

${ }^{57}$ C. A. 1772 [1927], 1994: 47. 
medicinas possíveis $e$, às vezes, também atuavam como médicos $e$ enfermeiros, manejando a lanceta por suas próprias mãos. ${ }^{58}$

Além das doenças já citadas, cabe uma observação acerca da forma como estas doenças eram descritas pelos padres, uma vez que o sintoma era contemplado como causa e, em outros casos, nem sempre era específico, deixando margem para interpretações. Dentre os sintomas citados, encontramos menções à estafa e ao esgotamento, que não estão necessariamente associados a determinada enfermidade que possa ter provocado o óbito. Há referência a dores no peito, que podem ser consideradas como sintomas tanto de doenças pulmonares, quanto cardíacas. Também encontramos menções às “angustias del corazón”, que parecem apontar para casos de apatia ou depressão entre os missionários. ${ }^{59}$ Localizamos, ainda, referências a frio nos ossos, sintoma que pode estar relacionado a problemas reumáticos, menções a vômitos e a febres, que, mais uma vez, podem estar relacionados a várias enfermidades, mas que nos necrológios são mencionadas como as causas mortis.

[...] Ya muy anciano, sufrió mucho de gota en pies y manos, quejándose, no de sus dolores, sino de su ociosidad, y de que le alimentaban de balde en la Compañía. Por esta razón, cuando en su enfermedad se le ofrecían aquellos alivios, que se suelen ofrecer a los enfermos, o para excitar su apetencia, o para levantar su buen humor, los rechazaba con inflexible modestia. Resplandeció sobre manera su paciencia en los tres últimos años de su grave y dolorosa enfermedad venciendo con ella los agijones de sus intolerables sufrimientos. [...] Resplandeció sobre manera su paciencia en los tres últimos años de su grave y dolorosa enfermedad venciendo con ella los agijones de sus intolerables sufrimientos. ${ }^{60}$

Nos necrológios que integram as Ânuas da segunda metade do século XVII, o maior número de óbitos registrados ocorreu nas reduções. Dentre as causas prováveis deste alto índice de mortalidade pode-se aventar a precariedade das instalações de muitas delas, que, geralmente, se encontravam localizadas em regiões distantes dos colégios, e o contato muito mais intenso com indígenas enfermos, em sua maioria, vítimas de epidemias. Os dados levantados parecem também indicar que os jesuítas com idade mais avançada - acima dos setenta anos - viveram seus últimos dias em colégios, como se constatou para o Colégio de Córdoba, enquanto que aqueles que tinham entre cinqüenta e sessenta anos, se encontravam atuando em reduções, quando de seu falecimento.

\footnotetext{
${ }^{58}$ Hernández, 1913: 16.

59 Judith Farberman, em Las Salamancas de Lorenza, refere-se ao diagnóstico “mal de corazón”, dado por duas curandeiras a Maria Antonia, que apresentava um quadro de "temblores, parálisis y mudez". A pesquisadora argentina - que se dedica ao estudo das práticas de feitiçaria e curandeirismo na região de Tucumán, durante o período colonial -, numa tentativa de explicação sobre o que consistia tal patologia, que integrava as enfermidades consideradas "naturales", afirma que "La denominación era por demás imprecisa, ya que abarcaba desde ciertas enfermedades bronquiales hasta la epilepsia y casi cualquier tipo de trastorno nervioso. "(Farberman, 2005: 227)
}

${ }^{60}$ C. A. $1658-1660$ [1927], 1994: 14-15. 


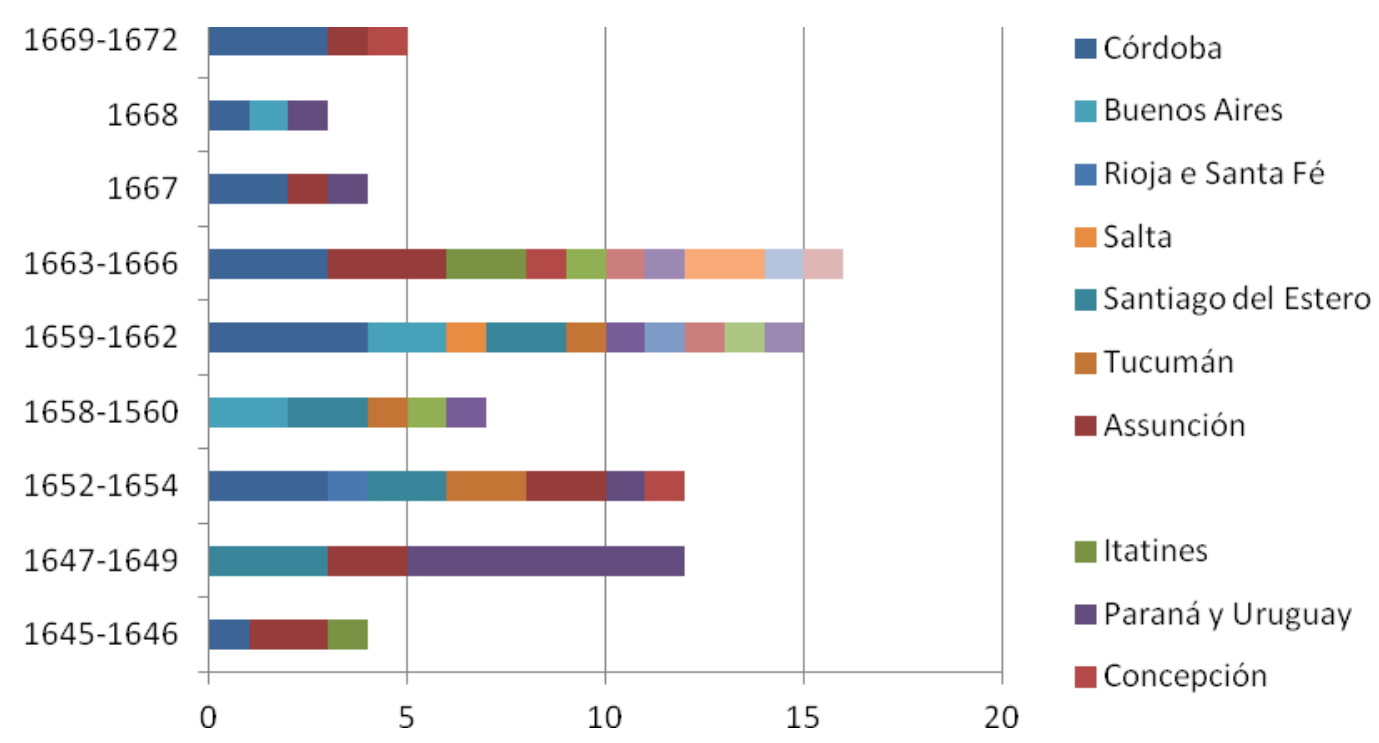

Figura 2 - de mortes de missionários por colégio/redução

Apesar dos óbitos de padres jovens que as Ânuas registram, a maioria dos missionários falecia já com idade avançada (vide Figura 3), contando com muitos anos de Companhia. Em grande parte dos casos, as mortes decorriam da saúde debilitada, devido à idade avançada, podendo ser agravada, ou não, por enfermidade. Dentre as moléstias que costumeiramente são associadas a pessoas idosas, e que são recorrentemente referidas nos necrológios, estavam artrites, reumatismos, complicações renais, gripes, febres e infecções. Cabe, no entanto, ressaltar que em um grande número de necrológios encontramos apenas a informação "causa desconhecida”, o que parece sugerir desconhecimento, ou, então, a preocupação do relator em registrar e valorizar muito mais a atitude do missionário diante da iminência da morte, do que a doença que o vitimou.

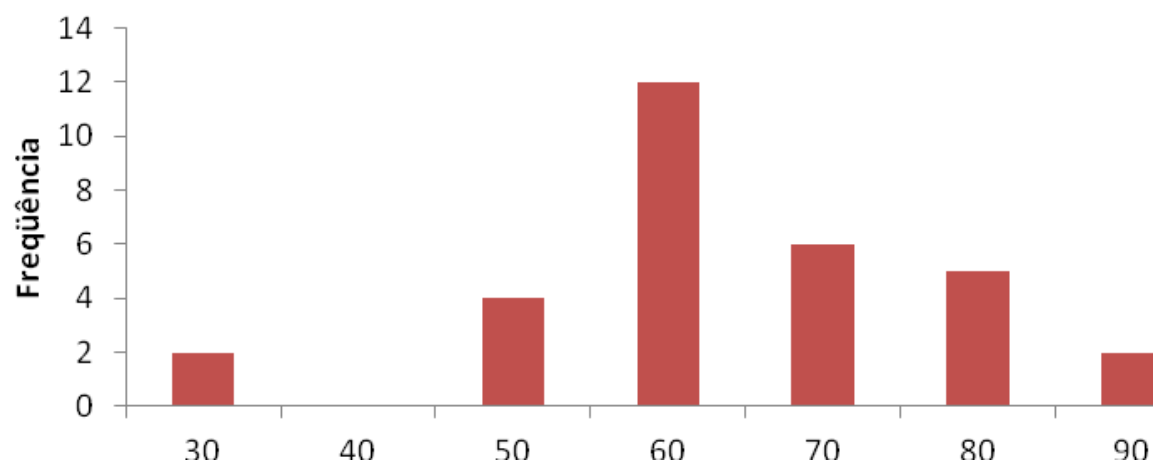

Figura 3 - Idade dos missionários ao falecerem

Dada a natureza edificante das Ânuas e a valorização das condutas exemplares nos necrológios, constata-se o destaque dado à vida virtuosa ${ }^{61}$ e à busca do martírio por muitos daqueles que mereceram o elogio fúnebre em seus obituários ${ }^{62}$, o que parece

\footnotetext{
${ }^{61}$ Vale lembrar o observado por Torres Londoño: “A edificação, assim, ganha nesse contexto, um traço de modernidade, onde através da escrita se colocava em evidência o real, além de uma releitura à luz da experiência de cristianização” (Torres Londoño, 2010: 21).

62 De acordo com Renato Cymbalista, a valorização do martírio se dava por guardar semelhança com o sofrimento experimentado por Cristo. A ideia de que este sofrimento aproximava os mártires dos santos
} 
apontar para a definição de um tipo de missionário ideal pela e para a Companhia de Jesus. Estes aspectos podem ser observados em uma passagem da Carta de 1647-1649, que refere que o irmão jesuíta Claudio Flores receberia grande honra após sua morte:

Al correr la noticia de la muerte del Padre, todo el mundo le apellidó mártir, y habló con el mayor respecto de él, diciéndose que era un varón de una virtud acabada, lleno de Dios y de un insaciable deseo de ganar almas para Cristo, nuestro Señor, un espíritu emprendedor irresistible cada vez cuando se trataba de promover la gloria de Dios. ${ }^{63}$

Como se pode constatar, morrer em martírio ou por qualquer outra privação (de alimento, por exemplo) não era algo assim tão temido pelos padres - jovens ou já com idade avançada -, na medida em que entendiam que todo o sofrimento enfrentado reverteria numa morte gloriosa, como se pode perceber no trecho abaixo:

Murió en este colegio en 1647 el Padre José Quevedo, natural de Córdoba del Tucumán, a la edad de 26 años, apenas acabados los estudios teológicos. Era muy devoto de María Santísima, de su virginal esposo, y de nuestros Santos, en cuyo honor había prometido ayunar en las vísperas de su fiesta a pan y agua. Así preparado no era de admirar, que sin miedo esperase la muerte. $^{64}$

A preocupação com a preparação para o descanso final, ${ }^{65}$ que garantia a boa morte, também fica evidenciada nas cartas, como se pode constatar nesta passagem:

Era un hombre muy piadoso y mortificado, y muy fiel en el cumplimiento de sus votos, y nadie le pudo sorprender en una falta contra ellos. [...]. Se le administraron los últimos sacramentos, después de lo cual decayó de fuerzas rápidamente, y pronto murió. ${ }^{66}$

A boa morte mencionada nas Ânuas está vinculada ao processo de provação e privação a que os missionários se submetiam, mediante rigorosa observância dos votos de pobreza e castidade e de uma vida de virtude e penitência, em nome da maior glória de Deus. Na iminência da morte, esta vida devotada seria ainda mais valorizada com a administração dos últimos sacramentos àqueles que eram merecedores da glória eterna, ${ }^{67}$ da boa morte. ${ }^{68}$ Também nos necrológios encontramos evidenciada a

acabava conferindo grande prestígio aos primeiros, por sua condição de modelo a ser seguido. A partir da era moderna houve, inclusive, a intensificação da circulação de obras que versavam sobre a imitação dos últimos momentos de Jesus. Ver mais em Cymbalista, 2011.

${ }^{63}$ C. A. 1647-1649 [1927], 1994: 62.

${ }^{64}$ Ibid.: 07.

65 É preciso considerar que para os cristãos dos séculos XVI e XVII, a “vida é apresentada (...) já não como o objeto de um julgamento, mas como a última oportunidade de provar a sua fé”. Em decorrência disso, a tradição cristã estabeleceu que a morte era uma espécie de sono profundo, mediado pela expectativa da ressurreição, quando as almas voltariam a habitar os corpos. Essa idéia introduziu uma nova percepção, que poupou gerações ao longo de séculos da idéia aterradora do fim definitivo. (Delumeau, 1991:156-157)

${ }^{66}$ C. A. $1652-1654$ [1927], 1994:15.

${ }^{67}$ Se o destino da alma causava o temor no homem setecentista, então os sacramentos, que contribuíam para a salvação, adquiriam grande importância e o medo de morrer sem eles era avassalador. A administração dos sacramentos de penitência, eucaristia e extrema-unção visavam ajudar o moribundo a ter uma boa morte. No discurso eclesiástico, os sacramentos da comunhão e extrema-unção dados ao moribundo perdoavam os pecados pendentes do enfermo, culpas esquecidas durante a confissão. Morrer 
percepção de morte e de morrer dos jesuítas, na medida em que estes obituários celebram aqueles missionários que, após vida virtuosa, longa enfermidade ou martírio, haviam demonstrado que "aprender a morir, significaba aprender a vivir adecuadamente", apontando para a utilização estratégica da "didactica del discurso [que] sabia poner ejemplos para concluir hacia una conversión de vida" pela Companhia de Jesus ${ }^{69}$.

\section{Considerações finais}

Nas Ânuas que analisamos, as mortes de missionários receberam atenção bastante diferenciada pelos padres relatores encarregados de sistematizar as informações provenientes das várias reduções, residências e colégios da Província Jesuítica do Paraguai. Na maioria delas, encontramos informações imprecisas acerca das razões para as mortes de padres e irmãos jesuítas, em algumas, a morte foi atribuída a um sintoma que está associado a várias enfermidades, dificultando o levantamento de causas mortis que pretendíamos realizar e, em outras, a violência com que foi executado o martírio ou os estágios de uma enfermidade foram detalhadamente descritos, visando à consagração póstuma do jesuíta. Este último aspecto fica bastante evidente nesta passagem que transcrevemos:

Consecuencia de tantos trabajos y privaciones era que cayó el Padre enfermo de la atroz enfermedad de lepra. Pero sospecho que él mismo se pidió del cielo semejante prueba; pues, al estar, un día, arrodillado delante del altar de la Virgen, pidió por gracia una enfermedad molesta, como penitencia por sus pecados. Parece que el cielo le mandó esta enfermedad al volver de la tierra de los guaycurúes. Propagóse pronto por todo su cuerpo, y le hizo sufrir horriblemente postrado en la cama por tres años y 2 meses, pelándosele todo el cutis, y volviendo cubrirlo de nuevo, desfigurándole formidablemente y privándole de la nariz. Estaba chorreando sangre y pus de los apostemas que le cubrían, así que uno no le pudo ver sin compasión. [...] Estaba siempre unido con Dios, haciendo continuamente actos de virtud heroica, hasta que pidió a Dios premiar su constancia, sacando su alma del cuerpo destrozado, para que viviese entre los bienaventurados del cielo. ${ }^{70}$

A ausência e a imprecisão das informações parecem apontar tanto para a pouca familiaridade dos padres relatores das Ânuas e dos necrológios com questões ligadas às artes de curar, quanto para a pouca importância que estas descrições tinham para um relato que deveria, observando as orientações de Inácio de Loyola, ser edificante e, sobretudo, exaltar a vida exemplar do falecido. A despeito dessas particularidades da documentação que consultamos, pôde-se constatar que dentre as causas mortis com

pecador significava ir para o Inferno, onde a alma sofreria eternos suplícios. Morrer sem estar em pecado mortal facilitava a ajuda dos santos e do anjo da guarda na salvação da alma. Assim, os últimos sacramentos, incluindo a confissão no leito de morte, perdoavam pecados e salvavam almas.

${ }^{68}$ Vale lembrar que o santo viático era administrado aos moribundos com o intuito de garantir a salvação de sua alma e que, durante sua administração, o cristão deveria avaliar sua vida e confessar-se.

${ }^{69}$ Sánchez, 2009: 530.

${ }^{70}$ C. A. 1663 [1927], 1994: 45. 
maior incidência estão aquelas associadas à idade avançada e as que decorriam das atividades ligadas às artes de curar que os missionários exerciam - nas reduções ou nos colégios -, e que os colocavam em contato direto com enfermos em estágios diferentes de doenças infecto-contagiosas ou não. Constatamos, também, que as doenças que acometiam padres e irmãos estavam necessariamente associadas ao meio e ao espaço de atuação no qual se encontravam inseridos. Os missionários que atuavam em reduções estavam sujeitos não apenas a uma maior exposição às epidemias que acometiam os indígenas, mas, também, a doenças reumáticas ou cardiotorácicas em decorrência do trabalho em regiões suscetíveis a inundações ou muito frias, ou, então, a doenças como “angústias del corazón”, que podiam estar associadas à tristeza e à solidão que os padres, em missão junto aos indígenas, sentiam. Em contrapartida, os colégios, instalados em áreas afastadas das reduções, contavam com boticas e enfermarias, o que parece explicar a incidência maior de registros de mortalidade relacionada a causas naturais, decorrentes, em grande medida, da idade avançada.

Nos necrológios, por sua vez, prevalecem a exaltação das virtudes e a descrição da trajetória - marcada por demonstrações de fé inabalável - do missionário na Companhia, não havendo maior preocupação do relator em descrever ou precisar a causa da morte, mas em ressaltar o empenho do padres em atender devotadamente " $a$ todas las necesidades espirituales de aquellos pobres indios"71. Além de trazer informações sobre como estes padres buscavam "la salud de las almas", enfrentando privações, ameaças constantes e obstáculos naturais para atender a grupos de indígenas, estes elogios fúnebres estão direcionados para a definição de modelos de conduta virtuosa que deveriam ser observados, apontando para a função pedagógica e de consagração póstuma que eles desempenhavam para a Companhia de Jesus. Evocados em alguns momentos da história da Companhia de Jesus, alguns desses homens virtuosos - como o padre Antônio Ruiz de Montoya - que escolheram "deliberadamente a possibilidade de perder [a vida], ao arriscar-se em cada confronto" garantiram a sua "sobrevivência em glória na memória dos homens que est[avam] por vir, [e assim] continuar a existir (...) em vez de desaparecer no anonimato do esquecimento"72. As descrições feitas sobre suas trajetórias exemplares como missionário e o destaque dado à resignação por eles demonstrada diante das enfermidades parecem ser os recursos narrativos necessários para a consagração da memória de padres que, como ele, "viveram como morreram, sempre santos".

Assim, a "muita tinta e [o] papel corrido"73 sobre a atuação exemplar de alguns padres e irmãos jesuítas - como as que encontramos descritas nas Ânuas e necrológios do século XVII e, também, nas biografias produzidas sobre eles - apontam para a reiteração de uma conduta virtuosa definida por Inácio de Loyola não apenas para os membros da Companhia de Jesus, mas para todos aqueles que buscam a salvação do corpo e da alma.

\footnotetext{
${ }^{71}$ Furlong, 1962: 604.

${ }^{72}$ Vernant, 2001: 410-411.

${ }^{73}$ Hansen, 2006; Luz, 2006: 12-13.
} 


\section{Referências}

Aguilar, Jurandir C. (2002), Conquista espiritual: A história da evangelização na Província Guairá na obra de Antônio Ruiz de Montoya, S. I. (1585 - 1652). Roma: Editrice Pontifícia Università Gregoriana.

Ariès, Phillipe (1982), O homem diante da morte. Rio de Janeiro: Editora Francisco Alves.

Barnadas, Joseph M. (2008), “A Igreja Católica na América Espanhola Colonial”. In. Bethell, Leslie (Org.), História da América Latina. vol. I: América Latina Colonial. São Paulo: Editora da Universidade de São Paulo, pp. 521-551.

Becker, Ítala I. (1992), "Lideranças Indígenas no começo das reduções jesuíticas da Província do Paraguay”, Revista Pesquisas - Instituto Anchietano de Pesquisas. São Leopoldo: IAP.

Berto, Carla (2005), Milagres constantes e inconstantes: variações no discurso jesuítico (1610-1640), Dissertação (Mestrado em História) -, Programa de PósGraduação em História- Pontifícia Universidade Católica do Rio Grande do Sul, Porto Alegre, RS.

Blumers, Teresa (1992), La contabilidad en las Reducciones Guaraníes. Asunción: Biblioteca Paraguaya de Antropología.

Bouza, Fernando (1999), Comunicación, conocimiento y memoria em la España de los siglos XVI e XVII. Salamanca: SEMYR.

Burrieza Sánchez, Javier (2009), Los jesuitas: de las postrimerias a la muerte ejemplar. Hispania Sacra, LXI, 124, julio-diciembre, pp. 513-544.

Cardozo, Efraim (1959), Historiografia Paraguaya. Mexico: Instituto Panamericano de Geografia e História.

Cartas Ânuas de la Provincia del Paraguay (C. A). Años 1645-1646. (1994) Versão da Tradução de Carlos Leonhardt, S.J. Buenos Aires, 1927. São Leopoldo, Instituto Anchietano de Pesquisas/UNISINOS.

Cartas Ânuas de la Provincia del Paraguay (C. A). Años 1647-1649. Versão da Tradução de Carlos Leonhardt, S.J. Buenos Aires, 1927.(1994) São Leopoldo, RS: Instituto Anchietano de Pesquisas/UNISINOS, 1994.

Cartas Ânuas de la Provincia del Paraguay (C. A). Años 1652-1654. Versão da Tradução de Carlos Leonhardt, S.J. Buenos Aires, 1927. (1994) São Leopoldo, RS: Instituto Anchietano de Pesquisas/UNISINOS.

Cartas Ânuas de la Provincia del Paraguay (C. A). Años 1658-1660. Versão da Tradução de Carlos Leonhardt, S.J. Buenos Aires, 1927. (1994) São Leopoldo, RS: Instituto Anchietano de Pesquisas/UNISINOS.

Cartas Ânuas de la Provincia del Paraguay (C. A). Anõs 1660-1662. Tradución de Carlos Leonhardt, S.J. Buenos Aires, 1927. Versão Tradução Digitada. (1994) São Leopoldo, RS: Instituto Anchietano de Pesquisas/UNISINOS. 
Cartas Ânuas de la Provincia del Paraguay (C. A). Año 1663. Versão da Tradução de Carlos Leonhardt, S.J. Buenos Aires, 1927. (1994) São Leopoldo, RS: Instituto Anchietano de Pesquisas/UNISINOS.

Cartas Ânuas de la Provincia del Paraguay (C. A). Anõs 1667. Tradución de Carlos Leonhardt, S.J. Buenos Aires, 1927. Versão Tradução Digitada. (1994) São Leopoldo, RS: Instituto Anchietano de Pesquisas/UNISINOS.

Cartas Ânuas de la Provincia del Paraguay (C. A). Anõs 1668. Tradución de Carlos Leonhardt, S.J. Buenos Aires, 1927. Versão Tradução Digitada. (1994) São Leopoldo, RS: Instituto Anchietano de Pesquisas/UNISINOS.

Cartas Ânuas de la Provincia del Paraguay (C. A). Anõs 1669-1672. Tradución de Carlos Leonhardt, S.J. Buenos Aires, 1927. Versão Tradução Digitada. (1994) São Leopoldo, RS: Instituto Anchietano de Pesquisas/UNISINOS.

Cartas Ânuas de la Provincia del Paraguay (C. A). Año 1772. Versão da Tradução de Carlos Leonhardt, S.J. Buenos Aires. (1994) São Leopoldo, RS: Instituto Anchietano de Pesquisas/UNISINOS.

Castelnau-L'Estoile, Charlotte de (2010), Operários de uma vinha estéril: os jesuítas e a conversão dos índios no Brasil 1580-1620. São Paulo: Editora EDUSC.

Chartier, Roger (2010), “Escutar os mortos com os olhos”, Estudos Avançados, vol. 24, n 69.

Cymbalista, Renato (2011), Sangue, ossos e terras: os mortos e a ocupação do território luso-brasileiro. São Paulo: Editora Alameda.

Delumeau, Jean (1990), História do medo no Ocidente: 1300-1800: uma cidade sitiada. São Paulo: Companhia das Letras.

Delumeau, Jean (1991), A confissão e o perdão. São Paulo: Companhia das Letras.

Del Valle, Ivonne (2009), Escribiendo desde los márgenes. Colonialismo y jesuítas en el siglo XVIII. México: Siglo XXI.

Eisenberg, José (2000), As missões jesuíticas e o pensamento político moderno. Editora UFMG, MG.

Farberman, Judith (2005), Las Salamancas de Lorenza. Magia, Hechicería y Curandeirismo en el Tucumán colonial. Buenos Aires: Siglo XXI Editores Argentina.

Fleck, Eliane Cristina Deckmann (2004), “A morte no centro da vida: reflexões sobre a cura e a não-cura nas reduções jesuítico-guaranis (1609-75)”, História, Ciências, Saúde-Manguinhos, Rio de Janeiro, RJ, v. 11, nº 03.

Fleck, Eliane Cristina Deckmann (2004), “Almas em busca de salvação: sensibilidade barroca no discurso jesuítico (século XVII)”, Revista Brasileira de História, São Paulo, SP, v.24, $\mathrm{n}^{\circ} .48$.

Fleck, Eliane Cristina Deckmann (2007), “Nas franjas do texto e do tempo: sensibilidade e espaço das experiências reducionais”, Revista de História USP, São Paulo, $\mathrm{n}^{\circ} 156$. 
Fleck, Eliane Cristina Deckmann (2005), "Sobre martírios e curas: medicina e edificação nas reduções jesuítico-guaranis (século XVII)”, Estudos IberoAmericanos. Porto Alegre, RS, v. XXXI, n ${ }^{\circ} 1$.

Franzen, Beatriz Vasconcelos; Fleck, Eliane Cristina Deckmann; Martins, Maria Cristina Bohn (organização, introdução e notas) (2008), Carta Ânua da província Jesuítica do Paraguai (1659-1662), São Leopoldo, RS: Oikos; Unisinos; Cuiabá, MT: EdUFMT.

Furlong SJ, Guillermo (1962), Misiones y sus Pueblos de Guaraníes. Buenos Aires: Teorema.

Furlong, SJ, Guillermo (1933), Los Jesuítas y la Cultura Rioplatense. Montevideo: Urta y Curbelo.

Furlong SJ, Guillermo (1964), Antonio Ruiz de Montoya y su carta a Comental, (1645). Buenos Aires: Theoría.

García Villoslada, Ricardo (1954), Manual de historia de la Compañia de Jesus. $2^{\mathrm{a}}$ edição. Madrid: Compañia Bibliográfica Española.

Halbwachs, Maurice (1990), A memória coletiva. São Paulo: Vértice.

Hansen, João Adolfo (2000), “A civilização pela palavra”. In: Lopes, Eliane M. Teixeira et alli, 500 anos de Educação no Brasil. Belo Horizonte: Autêntica.

Hernández SJ, Pablo (1913), Organización social de las doctrinas guaraníes de La Compañía de Jesús. Barcelona: Gustavo Gili.

Le Goff, Jacques (1989), O nascimento do purgatório. Lisboa: Editorial Estampa.

Leonzo, Nanci (1983), “O Culto aos mortos no século XIX: os Necrológios”. In: Souza Martins, José de (Org.), A Morte e os Mortos na Sociedade Brasileira. São Paulo: Hucitec.

Loyola SJ, Ignácio (2004) [1550], Constituições da Companhia de Jesus e normas complementares. São Paulo: Ed. Loyola.

Luz, Guilherme Amaral (2006), Carne humana: canibalismo e retórica jesuítica na América portuguesa (1549-1587). Uberlândia: EDUFU.

Maeder, Ernesto J. A. (1984), Cartas Anuas de la Provincia Jesuítica del Paraguay (1637-1639), Buenos Aires: FECIC.

Maeder, Ernesto (1985), “La “Conquista Espiritual” de Montoya y su alegato sobre las Misiones”. Teología, Revista de la Facultad de Teología de la Pontifícia Universidad Católica Argentina, ${ }^{\circ} 46$.

O’Malley, John W. (1993), The First Jesuits. Cambridge: Harvard University Press.

Rodrigues, Luiz Fernando Medeiros (s.d.), "A formula scribendi na Companhia de Jesus: origem, leitura paleográfica e fonte documental para o estudo da ação dos Jesuítas”. Anais. X Encontro Estadual de História. Disponível em http://www.eeh2010.anpuhrs.org.br/resources/anais/9/1279402723 ARQUIVO ST01-

Ahistoriografiaentreoparticular TextoAnaisdeLuizFernandoRodrigues.pdf. Acessado em 16/11/2011. 
Storni SJ, Hugo (1980), Catálogo de los Jesuitas de La Provincia del Paraguay (18751768), Roma: Institutum Historicum S.I.

Teschauer SJ, Carlos (1980), Vida e Obras do Preclaro Pe. Ruiz de Montoya, SJ. Apóstolo do Guairá e do Tape. Apresentação, transcrição, correção e notas do Pe. Arthur Rabuske SJ, Caderno de Pesquisas do IAP, História $n^{0}$ 19, pp. 230 240.

Torres Londoño, Fernando (2002), "Escrevendo Cartas. Jesuítas, escrita e missão no século XVI”. Revista Brasileira de História. São Paulo, ANPUH/Humanitas, v. $22, \mathrm{n}^{\circ} 43$.

Vargas Ugarte, Rubén (1941), Los Jesuitas del Perú (1568-1767), Lima: (s. e.).

Vernant, Jean-Pierre (2001), Entre Mito e Política. São Paulo: EDUSP.

Vilar, Socorro de Fátima Pacífico (2006), A Invenção de uma Escrita: Anchieta, os Jesuítas e suas Histórias. Porto Alegre: EDIPUCRS.

X(J)arque, Francisco (1900), Ruiz de Montoya en Indias (1608-1652). Madrid: Victoriano Suárez. 